\title{
Ectopic eruption of a lower permanent molar from the mediaeval necropolis of Alcáçova do Castelo, Mértola, Portugal
}

\author{
Inês Leandro ${ }^{\mathrm{a},{ }^{*}}$, Clara Rodrigues ${ }^{\mathrm{b}}$, Susana Gómez-Martínez ${ }^{\mathrm{b}}$, Cláudia Umbelino ${ }^{\mathrm{a}, \mathrm{c}}$ \\ ${ }^{a}$ Research Centre for Anthropology and Health (CIAS), University of Coimbra, Calçada Martim de Freitas, 3000-456 Coimbra, Portugal \\ ${ }^{\mathrm{b}}$ Campo Arqueológico de Mértola (CAM), Rua Dr. António José de Almeida no. 1, 7750-353 Mértola, Portugal \\ 'Department of Life Sciences, University of Coimbra, Calçada Martim de Freitas, 3000-456 Coimbra, Portugal
}

\begin{abstract}
The mediaeval necropolis of Alcáçova do Castelo is located in Mértola, Southern Portugal, and dates from the 14th to the 16th centuries. The archaeological campaigns started in 1978 and continue today, having yielded more than 759 graves. This report discusses an ectopic tooth eruption observed in skeleton 535, an adult female individual. A distal right permanent lower molar presents an ectopic eruption at the posterior margin of the coronoid process. On the opposite side, the first and second permanent molars are present, the left permanent lower third molar is absent and the mandibular ramus cannot be evaluated since it is broken off and lost. Tooth migration (heteropia) is a common pathological condition documented in clinical literature. However ectopic eruption of lower distal molars is a rare event, and there are few known cases. This is the first case described in archaeological populations worldwide.
\end{abstract}

\section{Keywords:}

Intraosseous tooth migration

Lower distal molar

Coronoid process

Oral pathology

\section{Introduction}

By definition tooth eruption is the axial or occlusal tooth movement from its intraosseous location within the jaw until it reaches its functional position in the occlusal plane of the oral cavity (Massler and Schour, 1941; Palma et al., 2003; Yaseen et al., 2011). Occasionally, teeth migrate from the eruption site and are found in distant locations from their normal anatomical position (Silva et al., 2007; Wong et al., 2007; Waldron, 2009). The aetiology of this migration is not fully understood (Wong et al., 2007; Wang et al., 2008) and seems to occur most frequently in the mandible with second premolars, canines, and lateral incisors most commonly affected (Silva et al., 2007). The clinical literature has many examples of tooth migration and eruption (Tümer et al., 2002; SuarezCunqueiro et al., 2003; Wong et al., 2007; Salmerón et al., 2008; Wang et al., 2008; Goyal et al., 2012; Iglesias-Martin et al., 2012; Payne et al., 2012). However, in the archaeological record only two instances of ectopic eruption have been recorded. A male individual over 45 yearsold, recovered from St. Peters's Collegiate Church 
(Wolverhampton, UK), dating to the mid-19th century, presents a right third molar impacted in the mandibular condyle (Ponce and Ogden, 2011). The other reported case describes an ectopic upper canine eruption on a young female individual from the Prehistoric American Southwest, who also presents an impacted lower first molar (Nelson, 2010). The present report describes the ectopic eruption of a lower distal molar in the posterior margin of the right coronoid process, in a skeleton retrieved from the mediaeval necropolis of Alcáçova do Castelo de Mértola, Southern Portugal. There are no records of similar cases in past populations.

\section{Case report}

The skeleton identified as CAM1995-A. Sep. 535, excavated in 1995, comes from the mediaeval necropolis of the Alcáçova do Castelo, located in Mértola, Southern Portugal (Fig. 1), dating from the 14th to the 16th centuries. The first archaeological excavations took place in 1978 under the supervision of Campo Arqueológico de Mértola (CAM); since then more than 759 graves have been excavated. The skeletal material retrieved from this necropolis has been curated at the Department of Life Sciences at the University of Coimbra. Skeleton 535 was inhumed in a decubitus dorsalis position with a west-east orientation, head to the west. The upper limbs and hands were crossed over the pelvic region. Despite poor preservation, very fragmented and incomplete, analysis revealed that it was a probable female, using Buikstra and Ubelaker (1994) and Wasterlain (2000) methodologies, and she was over 29 years of age, judging from the fusion of sternal ends of the both clavicles (MacLaughlin,1990). The skeleton was represented only by fragmented bones from the skull, upper limbs, shoulder girdle, sternum, cervical vertebrae, os coxae, hands and femora. The mandible presents an ectopic distal molar eruption at the posterior margin of the right coronoid process (Figs. 2 and 3). On the left side the lower first and second permanent molars are in their anatomical position, and the mandibular ramus cannot be evaluated since it is broken and lost (Fig. 4). The remaining teeth are present with the exception of the first left premolar, lost postmortem (Fig. 4). The left third molar is absent, but the presence of a distal contact facet on the left second molar led us to conclude that this tooth was lost antemortem. All upper teeth were in situ except the right central incisor, second right molar and first left molar that were lost postmortem. Dental wear affects all teeth, with grades varying from 3 to 7 according to Smith (1984) with the exception of the ectopic molar, which has none. Calculus is observed in almost all teeth, with grades between 1 and 2 (Brothwell, 1981). Dental enamel hypoplasias were registered in the lower incisors and canines and in the left upper canine and right lateral incisor. Cariogenic lesions were not found, and there is no evidence of any other dental pathologies. 


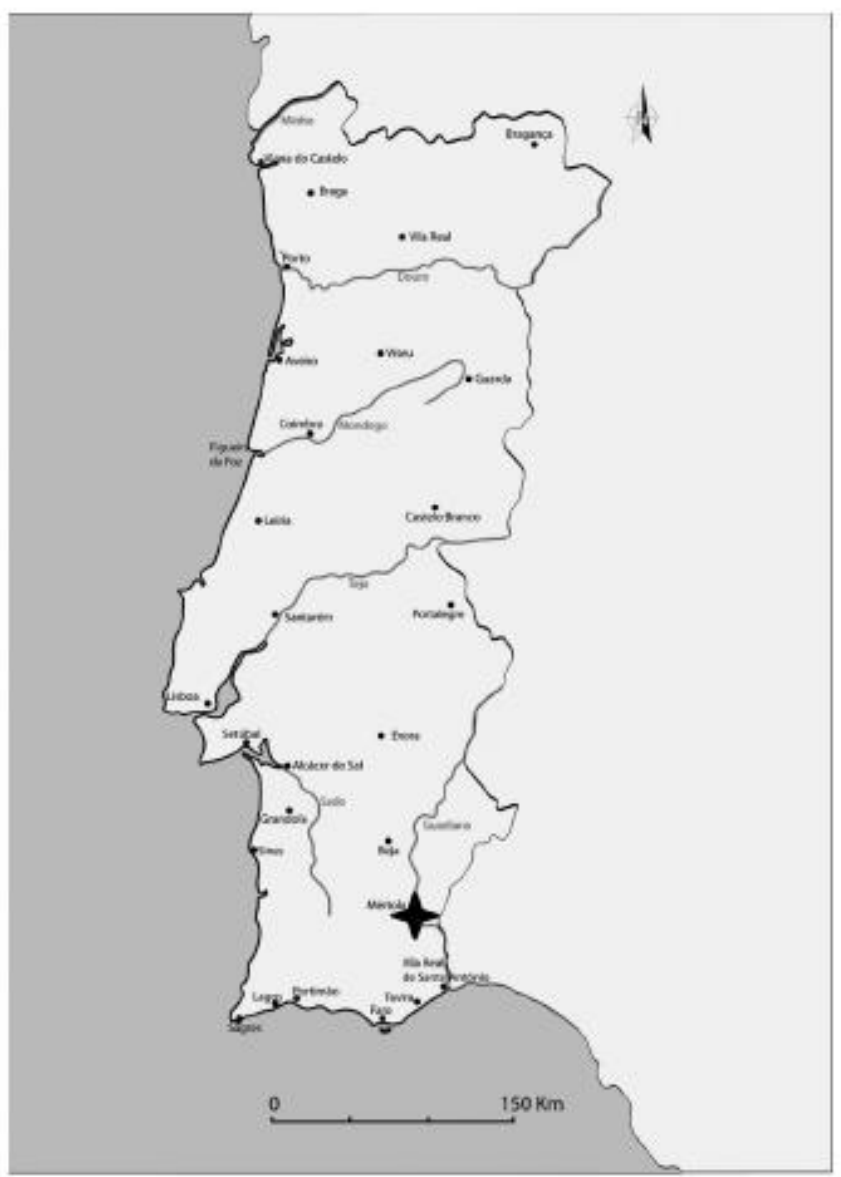

Fig. 1. Geographical location of Mértola, Southern Portugal.

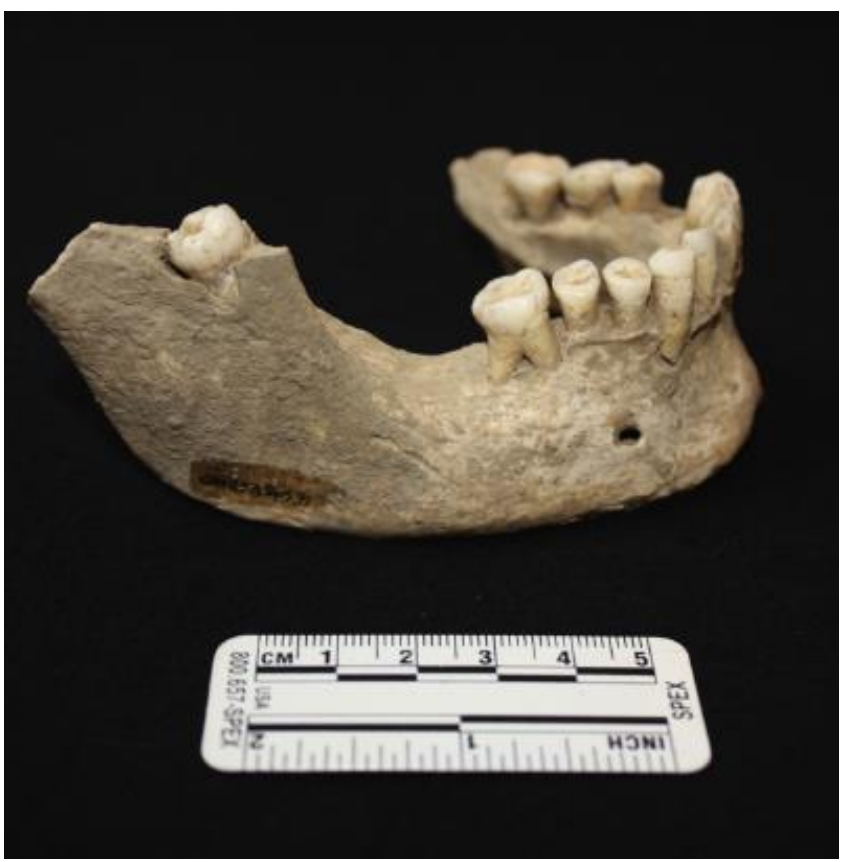

Fig. 2. Right lateral view of the mandible from the skeleton 535. 


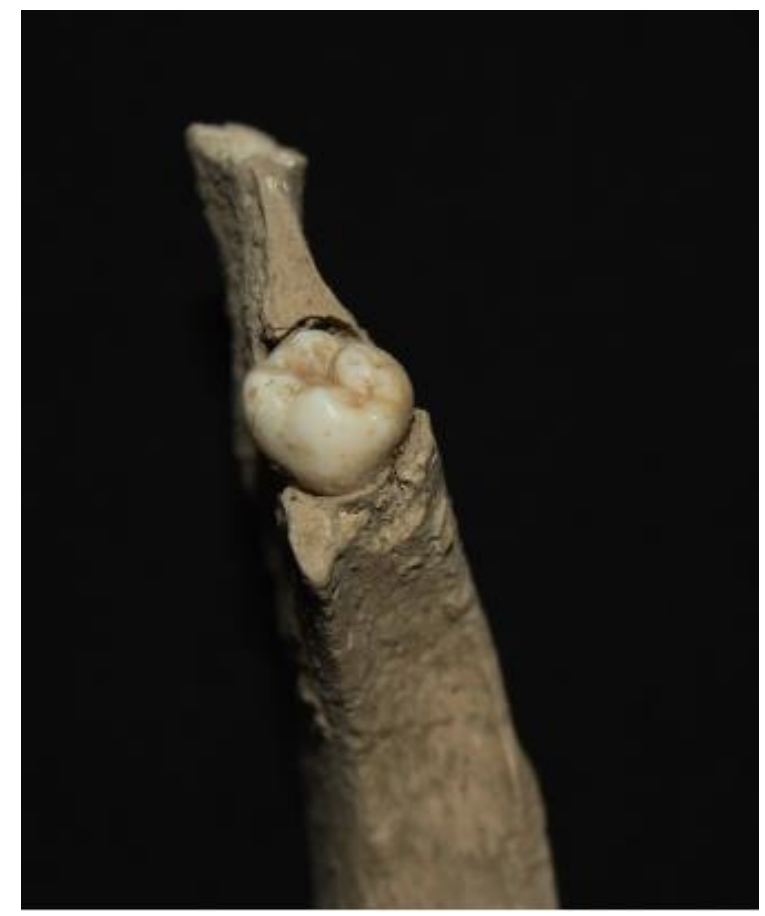

Fig. 3. Close up of the ectopic molar in the right posterior margin of the coronoid process.

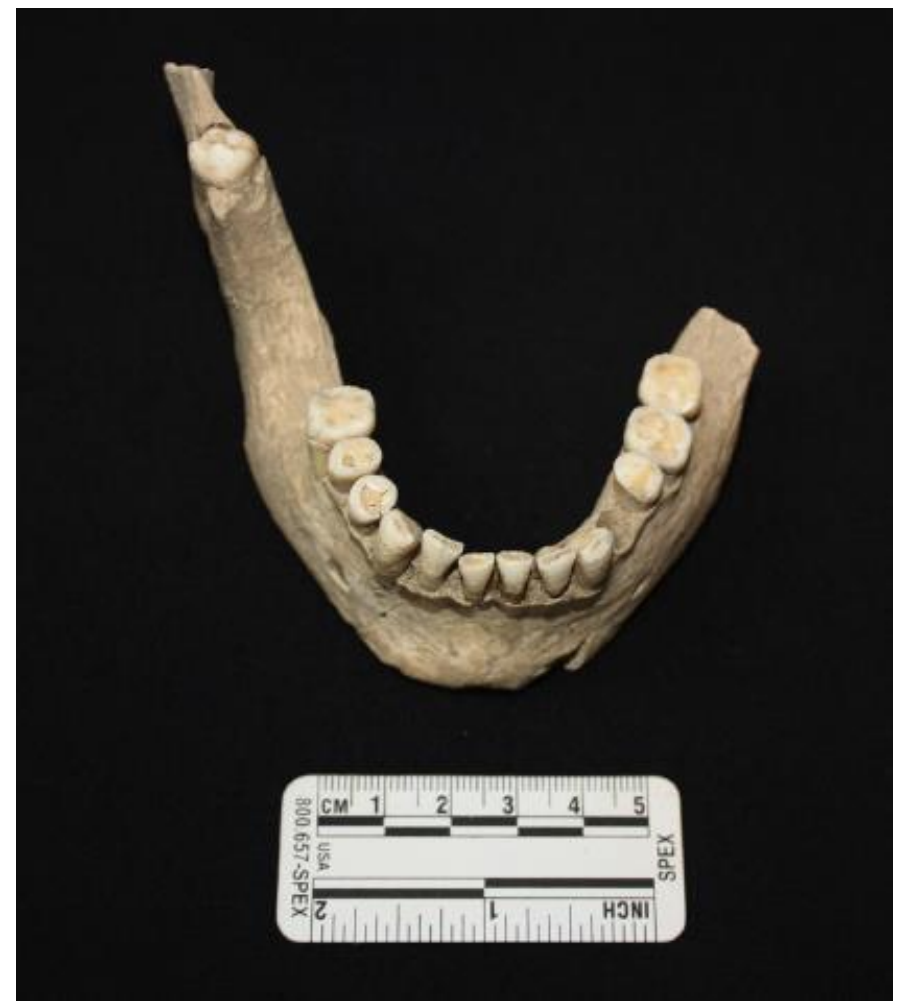

Fig. 4. Superior view of the mandible from the skeleton 535. 


\section{Discussion}

During the macroscopic and radiological analysis, doubts regarding the identification of the ectopic molar, whether it was a second or third, emerged. The number of cusps (five) and the fused roots suggest a third molar, since usually the second lower molar has four cusps, rectangular shape and two roots (Hillson, 1996; Scott and Turner, 1997). Nevertheless, the crown shape and size of the ectopic tooth is similar to that of the left second molar. According to Scott and Turner (1997), in 10-30\% of Western Europeans, second molars presents a crown with four main cusps and a very small hypoconulid. Furthermore, in 20-30\% of European groups, second molars presented fused roots (Scott and Turner, 1997). On the other hand, the right first lower molar does not present distal contact facets, but this characteristic only indicates that the second molar was not in contact with the first. This observation does not conclusively identify the ectopic tooth as a second molar. The absence of the right second molar on its correct normal anatomical position could result from impaction, agenesis, antemortem tooth loss or ectopic eruption. A radiographic survey showed no unerupted tooth in its expected position, so it is not a case of impaction. There are also no signs of alveolar resorption in the radiograph, but antemortem tooth loss long before death cannot be ruled out (Fig. 5). Macroscopically there is a depression in the right alveolar margin that could result from antemortem tooth loss or agenesis of the lower second molar. But according to Bondemark and Tsiopa (2007) this condition has a very low prevalence. These authors found a prevalence of $0.8 \%$ in a study performed between 2004 and 2006, in a Swedish population of 1543 patients, aged from 10 to 16 years. The likelihood of having two rare conditions in the same individual, such as the lower second molar agenesis and the third molar ectopic eruption, is unconvincing but cannot be excluded. The prevalence of ectopic eruption of the second molar is also very low (1.5\%) as noted by Bondemark and Tsiopa (2007). Therefore it is very difficult to accurately identify the ectopic tooth. We can only be certain that it is a distal molar. As outlined by Marques et al. (2013) "better a broader diagnosis than a misdiagnosis". Although its aetiology is not always possible to determine, an ectopic molar eruption may be the consequence of local iatrogenic activity (Silva et al., 2007; Wong et al., 2007; Wang et al.,2008; Kayal and Jayachandran, 2011; Iglesias-Martin et al., 2012; Shivashankara et al., 2012) The condition can occur in the mandibular condyle, the coronoid process, orbit, palate, nasal cavity, nasal septum, chin and maxillary sinus (Shivashankara et al., 2012). The main causes mentioned in the clinical literature for the occurrence of ectopic molars are trauma, ectopic formation of tooth germs, cysts and/or osseous or odontogenic tumors (Salmerón et al., 2008; Wang et al., 2008; Pace et al., 2010; Goyal et al., 2012; Iglesias-Martin et al., 2012). Ectopic molars are frequently associated with dentigerous cysts (Suarez-Cunqueiro et al., 2003; Salmerón et al., 2008; Payne et al., 2012). In our case, there is no evidences of dentigerous cysts or any other pathology in the mandible, so a developmental disorder seems to be the most probable cause. The most common symptoms associated with ectopic lower molars are pain and swelling on the ipsilateral side of the mandible, trismus, difficulty in mastication, cutaneous fistulae, temporomandibular joint disease and purulent discharge via intraoral or extraoral sinuses (Wang et al., 2008; Iglesias-Martin et al., 2012; Payne et al., 2012). 
The location of the ectopic eruption reported in the present work is unique. Cases of teeth erupting at sites different from their normal eruption location are frequently reported in clinical practice (Silva et al., 2007). However, a tooth that moves to such a distant place as the coronoid process is rarely found (Wong et al., 2007). Reported cases on molar migration are rare, and the most common are ectopic eruption of the upper first molars and lower lateral incisors (Wong et al., 2007) and inverted ectopic third molars located in the condylar or subcondylar region (Silva et al., 2007; Goyal et al., 2012; Iglesias-Martin et al., 2012). In a review of clinical literature on ectopic mandibular third molars, IglesiasMartin et al.(2012) found only 15 cases of ectopic lower third molars located, specifically, in the mandibular condyle. Between 1978 and 2003, Wang et al. (2008) recorded 13 cases in the ramus. The most recent clinical literature review lists 20 cases of ectopic lower third molars in the sigmoid notch (Findik and Baykul, 2015). There are no clinical literature reviews regarding ectopic lower second molars.

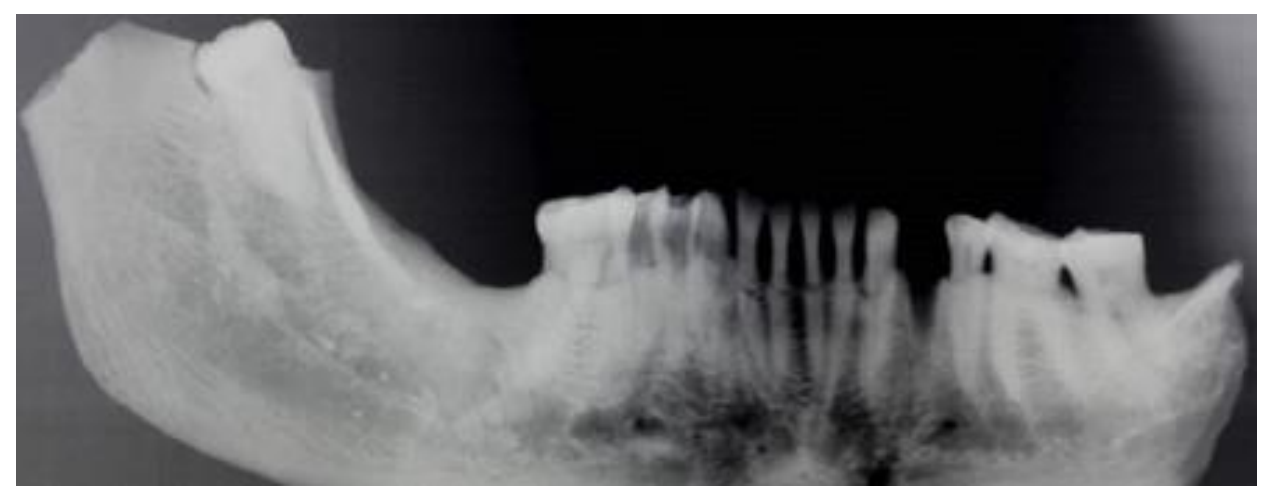

Fig. 5. Radiograph showing no unerupted tooth and the ectopic molar in the right coronoid process.

\section{Conclusion}

The condition observed in individual 535 from the mediaeval necropolis of Alcáçova do Castelo, in Mértola, Portugal, is very rare and represents the migration of a right lower distal molar and its subsequent ectopic eruption. There are no records of similar cases in past populations. The only case of molar migration found in the archaeological literature concerns a third permanent molar that was impacted in the right mandibular condyle (Ponce and Ogden, 2011), while in the clinical literature there are few documented cases of erupted or impacted ectopic second and third molars (Wang et al., 2008). Its description is therefore relevant in order to expand our knowledge on past dental developmental anomalies.

This research did not receive any specific grant from funding agencies in the public, commercial, or not-for-profit sectors. 
Conflict of interest

The authors have no conflict of interest to declare.

Acknowledgments

The authors wish to thank to Servic, o de Radiologia do Centro Hospitalar e Universitário de Coimbra, to Lucy Shaw Evangelista for the English revision and to the anonymous reviewers that helped improving the paper.

\section{References}

Bondemark, L., Tsiopa, J., 2007. Prevalence of ectopic eruption, retention and agenesis of the permanent second molar. Angle Orthod. 77 (5), 773-778.

Brothwell, D.R., 1981. Digging up Bones: the Excavation, Treatment and Study of Human Skeletal Remains. Cornell University Press, Ithaca, NY.

Buikstra, J.E., Ubelaker, D.H., 1994. Standards for Data Collection from Human Skeletal Remains. Archaeological Survey, Fayetteville, Arkansas.

Findik, Y., Baykul, T., 2015. Ectopic third molar in the mandibular sigmoid notch: report of a case and literature review. J. Clin. Exp. Dent. 7 (1), e133-e137.

Goyal, A.K., Gupta, D.S., Jain, R., 2012. Intraoral removal of bilateral ectopic third molar in the subcondylar and ramus regions: a rare case report. J. Stomat. Occ. Med. 5, 94-96.

Hillson, S., 1996. Dental Anthropology. Cambridge University Press, Cambridge.

Iglesias-Martin, F., Infante-Cossio, P., Torres-Carranza, E., Prats-Golezer, V., Garcia-PerlaGarcia, A., 2012. Ectopic third molar in the mandibular condyle: a review of the literature. Med. Oral Patol. Oral Cir. Bucal 17 (6), e1013-e1017.

Kayal, L., Jayachandran, S., 2011. Prevalence and distribution of dental anomalies in general population-an observational study. JIDA 5 (5), 612-615.

MacLaughlin, S.M., 1990. Epiphyseal fusion at the sternal end of the clavicle in a modern portuguese skeletal sample. Antropologia Portuguesa 8, 59-68.

Marques, C., Santos, A.L., Cunha, E., 2013. Better a broader diagnosis than a misdiagnosis: the study of a neoplastic condition in a male individual who died in early 20th century (Coimbra, Portugal). Int. J. Osteoarchaeol. 23 (6), 664-675.

Massler, M., Schour, I., 1941. Studies in tooth development: theories of eruption. AJO-DO 27 (10), 552-576. 
Nelson, G.C., 2010. Impacted lower first molar and labial ectopic upper canine eruption in an individual from the prehistoric American Southwest. Dent. Anthropol. 23 (3), 79-82.

Pace, C., Holt, D., Payne, M., 2010. An unusual presentation of an ectopic third molar in the condylar region. Aust. Dent. J. 55, 325-327.

Palma, C., Coelho, A., González, Y., Cahuana, A., 2003. Failure of eruption of first and second permanent molars. J. Clin. Pediatr. Dent. 27 (3), 239-246.

Payne, K., Dickenson, A., Patel, M., 2012. An unusually placed ectopic mandibular third molar: case report and discussion of management. Oral Surg. 5, 155-157.

Ponce, P.V., Ogden, A.R., 2011. Ectopic lower third permanent molar within the mandibular condyle: an archaeological example. Int. J. Osteoarchaeol. 23 (3), 367-369.

Salmerón, J.I., del Amo, À., Plasencia, J., Pujol, R., Vila, C.N., 2008. Ectopic third molar in condylar region. Int. J. Oral Max. Surg. 37, 398-400.

Scott, G.R., Turner II, C.G., 1997. The Anthropology of Modern Human Teeth: Dental Morphology and Its Variation in Recent Human Populations. Cambridge Studies in Biological and Evolutionary Anthropology, Cambridge.

Shivashankara, C., Manjunatha, B.S., Tanveer, A., 2012. Ectopic mandibular third molar in subcondylar region: report of a rare case. Oral Max. Surg. 16, 153-155.

Silva, G.C.C., Silva, E.C., Gomez, R.S., 2007. Migration of an unerupted second molar to the condyle: report of a case with sequential radiographs. J. Oral Maxil. Surg. 65, 570-572.

Smith, B.H., 1984. Patterns of molar wear in hunter-gatherers and agriculturalists. Am. J. Phys. Anthropol. 63, 39-84.

Suarez-Cunqueiro, M.M., Schoen, R., Schramm, A., Gellrich, N.-C., Schmelzeisen, R., 2003. Endoscopical approach to removal of an ectopic mandibular third molar. Br. J. Oral Maxillofac. Surg. 41, 340-342.

Tümer, C., Eset, A.E., Atabek, A., 2002. Ectopic impacted mandibular third molar in the subcondylar region associated with a dentigerous cyst: a case report. Quintessence Int. 33 (3), 231-233.

Waldron, T., 2009. Palaeopathology. Cambridge University Press, Cambridge.

Wang, C.-C., Kok, S.-H., Hou, L.-T., 2008. Ectopic mandibular third molar in the ramus region: report of a case and literature review. Oral Surg. Oral Med. Oral Pathol. Oral Radiol. Endod. 105, 155-161. 
Wasterlain, S.N., 2000. Morphé: análise das proporções entre os membros, dimorfismo sexual e estatura de amostra da colecção de esqueletos identificados do Museu Antropológico da Universidade de Coimbra. FCT; Universidade de Coimbra, Coimbra (Coimbra [Unpublished dissertation]).

Wong, Y., Liew, J.C., Tsui, S.H., Cheng, J.C., 2007. Ectopic molar near the coronoid process: case report. Quintessence Int. 38 (7), 597-600.

Yaseen, S.M., Naik, S., Uloopi, K.S., 2011. Ectopic eruption-a review and case report. Contemp. Clin. Dent. 2 (1), 3-7. 